\title{
A forester's guide to the environmental movement
}

\section{by Paul Griss}

One of the predominant environmental issues of the day is biodiversity. What I am going to do today is to give you an introduction to envirodiversity. The forest sector, in general, has failed to recognize the growing diversity of groups concerned about the environmental effects of forestry. Nowhere was this better demonstrated than in the invitation lists for the five regional fora reviewing the National Forest Sector Strategy recently staged by the Canadian Council of Forestry Ministers. I was stunned by the variation in these lists, with some provinces demonstrating a reasonably good understanding of their constituency, and others hopelessly mired in the past.

It would certainly be convenient if environmentalists could all be lumped together, but there is no one voice for the environmental movement. That doesn't stop the targets of their criticism from acting as if there were. Even today, federal Minister of Forestry, Frank Oberle, while advocating new partnership programs in forestry, couldn't resist a shot at the "preservationists", implying that anyone who calls for protection of Canada's forests is opposed to the forestry industry.

Despite the surge of public concern surrounding forest issues in the past few years, the forestry industry has been slow to get past the traditional knee-jerk approach of dismissing or discrediting those who question the status quo. If the sector is to address public concerns effectively, however, it must develop a better understanding of its critics and learn to identify who is who, and who it can work with.

\section{Canadian Environmental Organizations}

The Canadian Environmental Network claims that there are over 2000 environmental groups in Canada, and many more organizations are active on environmental issues to some degree. All these groups address different issues and in different ways, and they all have an important role to play. In the course of doing business, foresters could encounter at least fourteen different types of organization.

To prevent matters from becoming unduly complicated, I have restricted this review to groups whose primary orientation is towards either the environment or forestry. Those groups whose major concerns relate to the social, cultural, or economic aspects of forest issues (such as aboriginal groups, trade organizations, and social service agencies), are no less important and no less worthy partners. However, the environmental movement alone is sufficiently complex.

\section{(a) Evangelists}

Every movement has its lightning rods - high profile people who are articulate and emotional and can place issues firmly on the public agenda. These are the David Suzukis and Farley Mowats of the world. They aren't often interested in qualifiers or details. Rarely do they have organizational backing, but they can certainly command attention.

Executive Director, Canadian Nature Federation, 453 Sussex Drive, Ottawa, Ontario, Canada K1N 6Z4.

Presented to the Annual Conference of the Canadian Institute of Forestry, Toronto, September 25, 1991. (Prepared from Speaking Notes.)

\section{(b) Direct Action}

These groups believe in putting their bodies on the line for their beliefs. They don't compromise. Most sanction nonviolent protest, although some are more sanguine. Their highprofile tactics crystallize issues and bring them to public attention, but they aren't always willing to roll their sleeves up and work co-operatively for solutions. Groups in this category would include Greenpeace and Earth First!

\section{(c) Issue-oriented}

By far, the majority of groups fall into this category. Some are site-specific and can be identified by names such as "Friends of . . . ." Others may address a single environmental issue across a broad front, such as the Solar Energy Society of Canada. They are highly focused and may range from a handful of determined people to well-organized and well-funded groups.

\section{(d) Wilderness}

Foresters in the west will be very familiar with groups whose main priority is protecting wilderness lands from industrial development. Groups such as the Western Canada Wilderness Committee and the Canadian Parks and Wilderness Society are found in this category. Few oppose forestry - they are more concerned with where and how commercial forestry takes place. Many recreational groups interested in hiking, whitewater rafting, and similar pursuits often also fit within the wilderness category.

\section{(3) Resource Centres}

Across Canada, there are a variety of organizations that provide services to citizens or other organizations concerned with environmental issues. These groups offer research to enable others to better understand and address topics, and often play an investigative role.

\section{(f) Lawyers}

The environmental movement has its own legal department, with organizations existing to press for better environmental legislation, or to help individuals and other organizations challenge issues before the courts. The West Coast Environmental Law Association and the Canadian Environmental Defence Fund are examples. Canadian environmental issues have yet to become as litigious as those south of the border, but things seem to be moving in that direction.

\section{(g) Pollution}

Several national groups, such as Pollution Probe and Friends of the Earth, address a wide range of human impacts on the environment, principally those dealing with pollution. These groups are usually not active on resource management concerns, but are leaders in areas such as toxic chemicals, waste, and global warming, among others.

\section{(h) Naturalists}

Every province has its own naturalists society, like the Federation of Ontario Naturalists, and many communities also have such groups. Comprising individuals who are principally interested in understanding and enjoying nature in 
its broadest sense, many are also very active on environmental issues. These groups usually devote their attention to species that are not commercially valuable, and can therefore be excellent allies in addressing issues such as biodiversity.

\section{(i) Sportsmen}

Naturalist organizations are paralleled by sportsmen's groups, such as the Canadian Wildlife Federation and the Ontario Federation of Anglers and Hunters. These groups usually focus on the recreational interests of their members, which implies attention to game species and sport fish. Many are also active on other environmental issues.

\section{(j) Funders}

There are a variety of groups whose orientation is toward supporting others financially on conservation issues. Some, such as the Nature Conservancy of Canada, purchase land. Others, like Wildlife Habitat Canada and World Wildlife Fund (Canada), support a wide range of conservation activities, often in partnership with government or private funders.

\section{(k) Scientific}

Some groups, such as the Rawson Academy of Aquatic Sciences and the Royal Society of Canada, are technical in nature. When addressing issues, these groups tend to employ leading researchers and develop solid scientific backing for their conclusions. They aren't always visible, but they can be very influential.

\section{(l) Professional}

These include organizations whose support is largely derived from individuals professionally active in a field, such as the Canadian Institute of Forestry and the Canadian Society of Environmental Biologists.

\section{(m) Industry}

Most industries have their own associations, which are oriented at least partially toward environmental issues that address their sector. The Council of Forest Industries and the Canadian Pulp and Paper Association are obvious examples.

\section{(n) Multiple Use}

In recent years, a number of groups have sprung up to counteract those arguing for preservation of certain areas. These are commonly called "Share the ... " and are usually comprised of individuals dependent economically on the commercial development of the area in question.

\section{Addressing Environmental Issues}

The forestry industry is well behind many other sectors of the economy in its attempts to deal with environmental organizations and the environmental concerns of the general public. Confrontation has dictated the agenda to date, from site-specific disputes, such as Carmanah and Temagami, to broader issues, such as the proposed European boycott of Canadian forest products. It is a pattern all too familiar. The same approach was used by the sealing and fur industry, to no avail. In contrast to those issues, however, alliances are now forming between environmentalists, labour, and aboriginal peoples, making the opposition to the status quo in forestry even more potent.

Site-specific disputes affect less than $1 \%$ of the forested lands in Canada, and it is ridiculous to attempt to deal with the environmental issues facing all forestry operations with the same confrontational tone. Despite the fact that carbon emissions are causing some of our most serious environmental problems, oil and gas companies don't have the public stigma that is presently attached to forestry companies. This doesn't mean that they aren't in the thick of environmental battles, they've just learned to address criticism more effectively. If we are to work together more constructively, we need to see continued progress by the forest sector in five major areas.

Firstly, the sector needs to be pro-active rather than reactive in addressing public concerns. Calling for advertiser boycotts due to television programs that are critical of forestry only further damages the industry's own credibility. The forest sector should be its own most severe critic. It should publicly acknowledge the problems and strive constantly for improvements in environmental performance.

The substance of public concerns also needs to be addressed rather than dismissed. McDonald's changed from polystyrene packaging to paper not because it was ultimately proven to be right, but because their customers demanded the change. The costs involved in debating the issue with customers while awaiting a definitive answer would have been too damaging. The Canadian Chemical Producers Association has developed Responsible Care to address public concerns about chemical production and use. The forestry industry should be learning from these efforts.

The Canadian Pulp and Paper Association, in contrast, produced glossy ads telling the public that everything is okay in Canada's forests. This leads to the next requirement, which is a shift to communications from public relations. The forestry industry's communications programs have been generally poor, and it is no surprise that industry usually gets the short end of the stick in public debates. If the public doesn't understand the issues, it is because the industry itself has not properly communicated information.

Related to the above is the need to treat the public with respect rather than contempt. Methods need to be developed to secure meaningful public input into forest management decision making. Too often, the emphasis is on briefings, which provide information after decisions have been made, allowing questions but no real debate. Like it or not, the public are the ultimate decision makers in this country, and if the industry wants them on side then it needs to get them involved.

Finally, we need co-operation rather than confrontation. This is slowly starting to happen through exercises such as the forests dialogue of the National Round Table on the Environment and the Economy, the Canadian Forestry Association's ENVIROFOR, the recently announced Partners in the Sustainable Development of Forests program, and the initiatives of several forestry industries.

Knowing what has to be done, and knowing who is out there to help, are prerequisites for success. The difficult part then becomes putting the partherships together.

\section{Identifying Partners}

In order to make progress in the areas described above, the forest sector is going to have to learn to differentiate 
between the multitude of critics and identify which ones can be constructive partners. The groups to be considered will obviously depend on the issue to be addressed, or the region of concern. However, there are a number of factors that need to be examined to ensure that you find a compatible partner.

\section{(a) Motivation}

What is the group in question trying to achieve? Are they interested in forestry, or are they simply using forestry to advance another agenda? Can they co-operate with you or does their mandate prevent such actions? The answers to these need not preclude partnerships - in some cases groups not uniquely oriented towards forestry may make very suitable partners. It all depends on what you want to achieve. Try to get beyond the posturing to identify what your potential partner is really trying to accomplish.

\section{(b) Tactics}

Where do you see the group? Is your main contact with them through the media or in public fora? Do they participate in consultation exercises or do they boycott such events? I once heard a prominent wilderness activist complain that her group had had little impact on senior officials in government and industry despite strong public support. The reason is that contacts with those decision makers were never cultivated. Smart groups will adapt their tactics to circumstances, so even though the group may be confrontational, it may react positively to a partnership if given the opportunity.

In trying to deal with many environmental groups, you must also overcome their mild tendency toward paranoia. Some genuinely believe that as soon as they sit around a table behind closed doors they will be co-opted and taken advantage of. Whether this happens or not depends largely on the validity of the group's views and the calibre of its representative. However, partnerships are as new to many environmental groups as they are to forestry companies, and sensitivity needs to be shown to the difficulties that a change of tactics will present to many potential partners.

\section{(c) Time Horizon}

Every group has a time horizon on which it operates. Admittedly, the time horizon of most environmental organizations is short, particularly if they want logging stopped in a certain area. If a group expects improvements now, they will have difficulty working constructively with an industry with the time lines of forestry. Can they commit over the long haul?

\section{(d) Track Record}

Obviously, you don't want to establish a partnership with a group that could be here today and gone tomorrow. How long has the group been around? What other issues have they addressed? What are the qualifications of the group's leaders? For more established groups, a check with other industries or appropriate government departments can give an indication of the approach taken to other issues. On many issues, particularly those of a local nature, groups may only have formed recently. In these cases, you will need to rely heavily on the reputation of the individuals comprising the group.

\section{(e) Programs}

Is the group oriented towards a specific issue or does it offer a range of programs? Is it local in approach, or does it have provincial, national, or international scope? Is it a volunteer organization or does it employ paid staff? This will help you to identify two things: what proportion of the organization's time can be devoted to your undertaking; and what resources and expertise they can bring to the table.

Many environmental organizations rely on the energies of one or two key individuals, and consequently have little depth. If these people become over-committed, or leave, your partnership will suffer. And one of the biggest failures of consultation exercises is the persistent difficulty in recognizing the problems faced by volunteers.

While representatives of government and industry, and staff members of larger environmental organizations are usually paid to participate, the majority of environmental organizations thrive on volunteers. Often these people must take time off work, or even take vacation, to participate in conferences or other activities. Treat their commitment with genuine respect, even if you are in complete disagreement with them.

\section{(f) Public Support}

Every environmental organization claims to represent the public, if only because they don't speak for industry or government. Often groups claim to represent hundreds of thousands of Canadians. How do you determine if they really do, or are simply a vocal minority?

One way is funding. Generally speaking, if the public agrees with a cause it will support it. However, this maxim must be applied with caution. Most environmental organizations are more concerned with working on issues than in developing the support base to underwrite that work, leading to frequent complaints about lack of funds. Newly-formed groups will not yet have attracted a base of support and it will take a careful reading of other factors to determine whether they are in line with public opinion. Still others may be coalitions of organizations, that will have few direct members themselves. If so, you need to ascertain what sort of authority is granted to the coalition by the member organizations.

It is not always advantageous to only consider groups that claim a large public support base. Another maxim states that it's more important to reach the people who count than to count the people you reach. The type of people the group represents is as important as the number.

\section{(g) Accountability}

This is probably the most important attribute you want in a partner. How is the group governed? Is the scope and mandate of the organization reflected in the representation on the board of directors? Is the board of directors self-appointed or are directors elected by a broader membership? The word member means different things in different organizations.

Few environmental organizations, particularly at the national level, allow their individual supporters to be voting members, making accountability more difficult to ascertain. Be very careful of groups that expect the forest sector to be accountable and yet do not divulge information on their fundraising, spending or decision making, even, in some cases, to their supporters.

\section{Working with the Environmental Movement}

The environmentalists that have caused the current consternation in the Canadian forestry industry only represent 
one segment of the environmental movement. These groups have a perfectly legitimate role and have played it well, because they have helped to place concerns over forest management firmly on the public agenda. Now that we've got your attention, there are two paths that can be followed. You can either continue to fight, and engage in a polarized battle for public opinion, or you can address the substance of public concerns working in partnership with a tremendous array of environmental organizations.

The tide is turning away from rhetoric and confrontation toward more co-operation and partnerships. Confrontation over certain sites and techniques is inevitable and will continue. However, if good working relationships can be established on the broader issues, then it will be much easier to resolve the conflicts. Above all, the confrontations cannot be allowed to dominate or counteract other approaches to addressing forest management issues on the rest of the landscape.

The forest sector is still largely ignorant of its critics, and that is a very dangerous position in which to be, particularly in these volatile times. Hopefully, my remarks have served to give you an overview of the plethora of environmental organizations in Canada, enable you to distinguish between the players, and provide some ideas for selecting partners. There is a lot of work to do in Canada's forests, and while foresters may presently feel besieged, there are a number of groups willing and able to play a constructive, partnership role in doing that work. Nobody is going to be able to do it alone.

\section{CIF/IFC Corporate Sustaining Members}
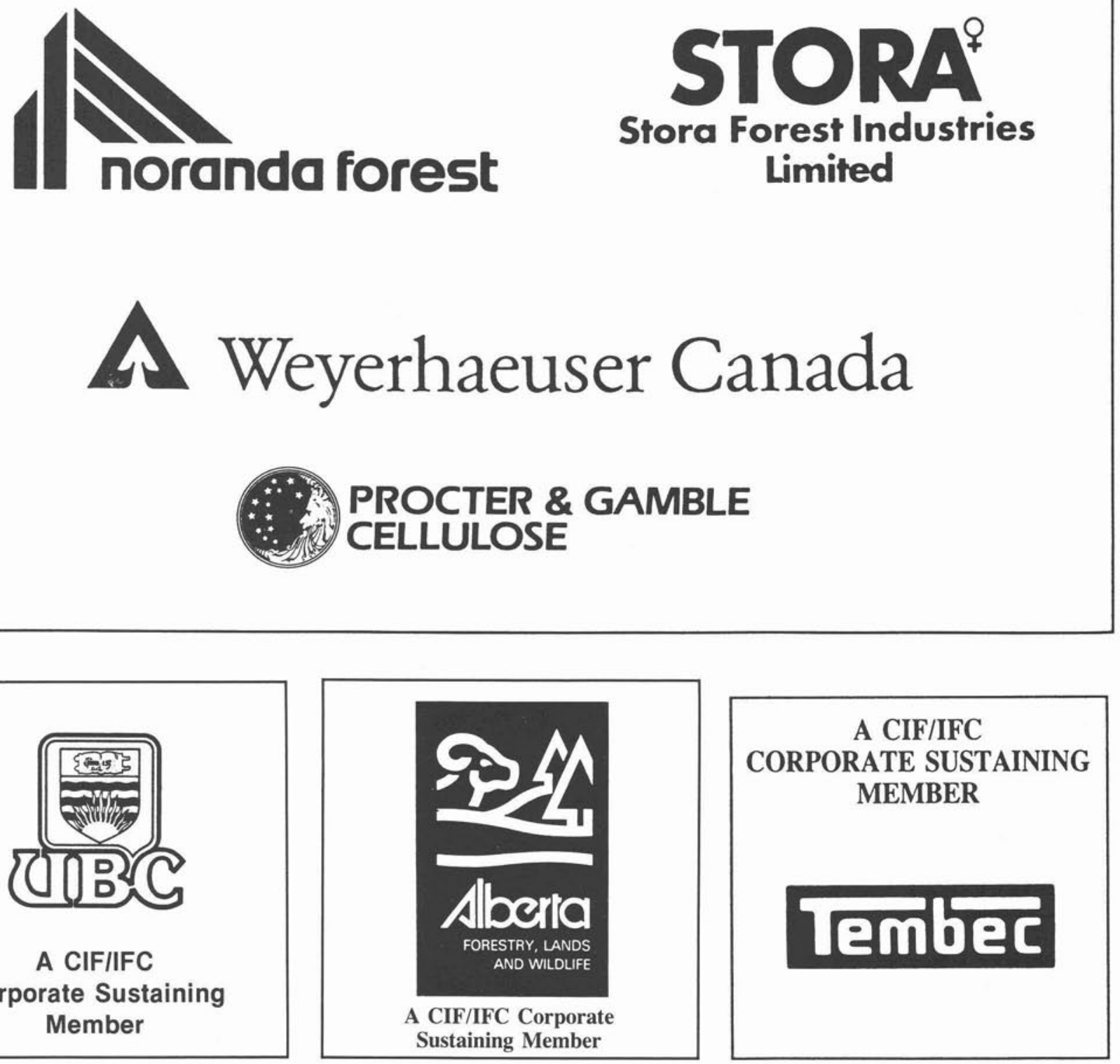